\title{
On the $\mathrm{Sn}$ loss from thin films of the material system $\mathrm{Cu}-\mathrm{Zn}-\mathrm{Sn}-\mathrm{S}$ in high vacuum
}

\author{
A. Weber, ${ }^{a)}$ R. Mainz, and H. W. Schock \\ Helmholtz-Zentrum Berlin für Materialien und Energie, Glienicker Str. 100, D-14109 Berlin, Germany
}

(Received 24 September 2009; accepted 17 November 2009; published online 12 January 2010)

\begin{abstract}
In this paper the $\mathrm{Sn}$ loss from thin films of the material system $\mathrm{Cu}-\mathrm{Zn}-\mathrm{Sn}-\mathrm{S}$ and the subsystems $\mathrm{Cu}-\mathrm{Sn}-\mathrm{S}$ and $\mathrm{Sn}-\mathrm{S}$ in high vacuum is investigated. A combination of in situ $\mathrm{x}$-ray diffractometry and $\mathrm{x}$-ray fluorescence (XRF) at a synchrotron light source allowed identifying phases, which tend to decompose and evaporate a Sn-containing compound. On the basis of the XRF results a quantification of the Sn loss from the films during annealing experiments is presented. It can be shown that the evaporation rate from the different phases decreases according to the order $\mathrm{SnS}$ $\rightarrow \mathrm{Cu}_{2} \mathrm{SnS}_{3} \rightarrow \mathrm{Cu}_{4} \mathrm{SnS}_{4} \rightarrow \mathrm{Cu}_{2} \mathrm{ZnSnS}_{4}$. The phase $\mathrm{SnS}$ is assigned as the evaporating compound. The influence of an additional inert gas component on the $\mathrm{Sn}$ loss and on the formation of $\mathrm{Cu}_{2} \mathrm{ZnSnS}_{4}$ thin films is discussed. (C) 2010 American Institute of Physics. [doi:10.1063/1.3273495]
\end{abstract}

\section{INTRODUCTION}

The compound semiconductor $\mathrm{Cu}_{2} \mathrm{ZnSnS}_{4}$ has gained interest in the past years as its physical properties make it suitable as an absorber material for thin film photovoltaic devices. ${ }^{1,2}$ Its crystalline structure is commonly referred to as the kesterite type..$^{3-5}$ This structure is strongly related to the chalcopyrite structure of the well known photovoltaic absorber material $\mathrm{Cu}(\mathrm{In}, \mathrm{Ga}) \mathrm{Se}_{2}{ }^{6}$ Starting from $\mathrm{Cu}(\mathrm{In}, \mathrm{Ga}) \mathrm{Se}_{2}$ the kesterite structure can be obtained by replacing In and $\mathrm{Ga}$ with $\mathrm{Zn}$ and $\mathrm{Sn}$ and Se with S. Such a replacement may be interesting as $\mathrm{Zn}, \mathrm{Sn}$, and $\mathrm{S}$ are much more abundant in Earth's crust than In, Ga, and Se. Up to now the best solar cells based on $\mathrm{Cu}_{2} \mathrm{ZnSnS}_{4}$ are formed by annealing metallic and sulfidic precursor layers in a sulfur containing atmosphere for several hours. These absorbers reach energy conversion efficiencies of $6.7 \%{ }^{2}$ The efficiency and also the long processing times are still unsatisfactory. Some attempts $^{7-10}$ have been made to use physical vapor deposition (PVD), which is successfully used for the deposition of $\mathrm{Cu}(\mathrm{In}, \mathrm{Ga}) \mathrm{Se}_{2},{ }^{11}$ to shorten growth times and to improve process control and process reproducibility. In an earlier work ${ }^{9}$ we found in accordance with Ref. 7 that the Sn content of the layers decreases with increasing substrate temperatures during such a PVD process. This effect may be explained either by a decreasing adsorption of $\mathrm{Sn}$ atoms on the substrate surface or by the re-evaporation of $\mathrm{Sn}$ or a $\mathrm{Sn}$ compound from the deposited layer. In this work we investigate the latter possibility on the basis of an experimental series on precursor layers of the material systems $\mathrm{Sn}-\mathrm{S}, \mathrm{Cu}-\mathrm{Sn}-\mathrm{S}$, and $\mathrm{Cu}-$ $\mathrm{Zn}-\mathrm{Sn}-\mathrm{S}$. We detect changes in the elemental composition and the phase composition during a heating experiment by a combination of in situ x-ray fluorescence (XRF) and x-ray diffraction (XRD). We will discuss how the $\mathrm{x}$-ray signals can be used for the quantitative evaluation of the Sn content of the layers and the influence of an additional gas atmosphere on the Sn loss at elevated temperatures.

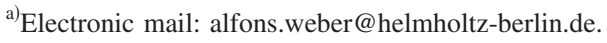

\section{EXPERIMENTAL}

Precursor layers were deposited on Mo-coated soda-lime glass substrates in a PVD system with elemental sources of $\mathrm{Cu}, \mathrm{Sn}$, and $\mathrm{S}$ and binary sources of $\mathrm{ZnS}$ and $\mathrm{SnS}$. The PVD system allowed depositing layered films of different binary sulfides as well as homogeneously coevaporated films. Thin films of the three different material systems $\mathrm{Sn}-\mathrm{S}, \mathrm{Cu}-\mathrm{Sn}-\mathrm{S}$, and $\mathrm{Cu}-\mathrm{Zn}-\mathrm{Sn}-\mathrm{S}$ were prepared. The material amounts of all films were aimed for a $2 \mu \mathrm{m}$ thick layer of $\mathrm{Cu}_{2} \mathrm{ZnSnS}_{4}$. The evaporation rate was measured by a calibrated quartz crystal monitor. The error of the measurement is approximated to be less than $15 \%$. Table I gives an overview of the different film types. For each material system two types of precursors were grown: one with a homogeneously coevaporated film and one with a layered film. The layered films were of the sequence glass $/ \mathrm{Mo} / \mathrm{SnS} / \mathrm{CuS} / \mathrm{ZnS}$. This sequence was used to evaluate the effect of covering the Sn-containing part of the film on the Sn loss from the layers.

The Sn-loss experiments on these precursors were carried out in a vacuum chamber equipped with a heatable substrate stage and a Knudsen-type sulfur source (S-source). The base pressure of the chamber was approximately 1 $\times 10^{-3} \mathrm{~Pa}$. During the Sn-loss experiment the S-source was operated at a temperature of $180{ }^{\circ} \mathrm{C}$, which leads to a chamber pressure of $1 \times 10^{-2} \mathrm{~Pa}$. The heating of the sulfur source started 20 min before the substrate was heated to assure a

TABLE I. Overview of different investigated precursors (slashes mark the interfaces, and coevaporated elements are catenated with "+"). The Sn amount was derived from the $\mathrm{Sn}$-deposition rate.

\begin{tabular}{ll}
\hline \hline Layer structure & $\begin{array}{c}\text { Sn amount } \\
\left(\text { at. } / \mathrm{cm}^{2}\right)\end{array}$ \\
\hline $\mathrm{Mo} / \mathrm{Sn}+\mathrm{S}$ & $1.2 \times 10^{18}$ \\
$\mathrm{Mo} / \mathrm{Cu}+\mathrm{Sn}+\mathrm{S}$ & $1.1 \times 10^{18}$ \\
$\mathrm{Mo} / \mathrm{Cu}+\mathrm{Zn}+\mathrm{Sn}+\mathrm{S}$ & $1.0 \times 10^{18}$ \\
$\mathrm{Mo} / \mathrm{SnS}$ & $1.1 \times 10^{18}$ \\
$\mathrm{Mo} / \mathrm{SnS} / \mathrm{Cu}+\mathrm{S}$ & $1.1 \times 10^{18}$ \\
$\mathrm{Mo} / \mathrm{SnS} / \mathrm{Cu}+\mathrm{S} / \mathrm{ZnS}$ & $1.1 \times 10^{18}$ \\
\hline \hline
\end{tabular}




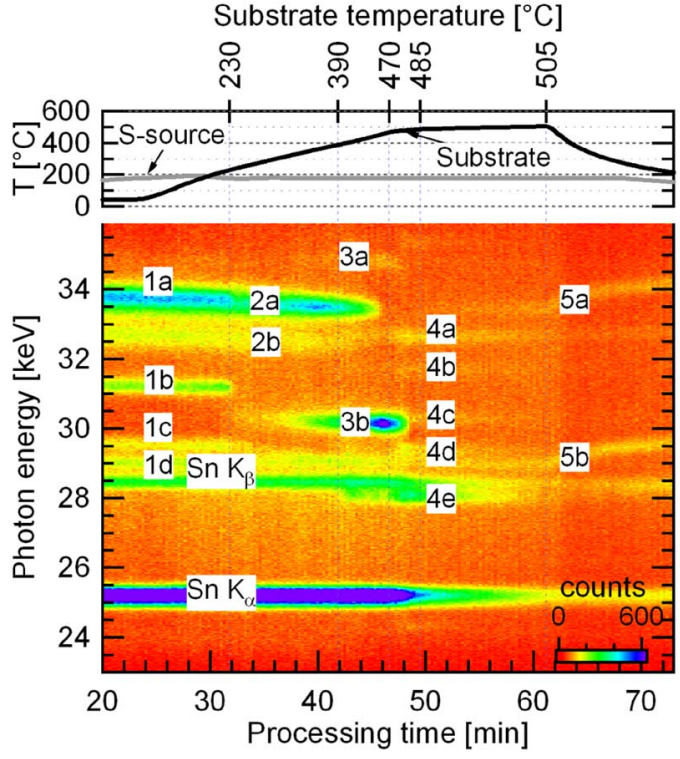

FIG. 1. (Color online) Two-dimensional representation of the detected energy dispersive signals (bottom part of the graph) during the heating program (top part of the graph) on a precursor of the structure $\mathrm{Mo} / \mathrm{SnS} / \mathrm{CuS}$. The following phases can be identified: CuS (Ref. 13) [(1a) hkl=103, (1b) 102, (1c) 101, and (1d) 100], SnS (Ref. 14) [(2a) 111 and (2b) 101], $\mathrm{Cu}_{2} \mathrm{SnS}_{3}$ (Ref. 15) [(3a) 131 and (3b) - 131], $\mathrm{Cu}_{4} \mathrm{SnS}_{4}$ (Ref. 16) [(4a) 112, (4b) 221, (4c) 102, (4d) 121, and (4e) 220], and $\mathrm{Cu}_{2-\mathrm{x}} \mathrm{S}$ (Ref. 17) [(5a) 200 and $(5 b) 111$.

constant S-pressure. The pressure was measured by a Bayard-Alpert hot cathode vacuum gauge attached to the vacuum chamber. In the standard experiment the substrate was heated for $25 \mathrm{~min}$ from room temperature to a nominal temperature of $550{ }^{\circ} \mathrm{C}$. The nominal temperature was measured by a thermocouple in the heating zone; the temperature of the thin film was measured by a Pt100 attached to the substrate surface. All further temperature values will refer to the Pt100 measurement unit.

The vacuum chamber was mounted on the beamline F3 of the HASYLAB synchrotron source. Polychromatic synchrotron radiation enters through a polyimide window and interacts with the film. Under an angle $2 \Theta$ of $7.5^{\circ}$ the diffraction and fluorescence signals exit the chamber through a second polyimide window and are detected energy dispersively in the energy range between 5 and $55 \mathrm{keV}$. Every $15 \mathrm{~s}$ a complete spectrum is recorded, which allows for a high time resolution of the signals during the experiment. Further details on the measurement setup can be found elsewhere. ${ }^{12}$

Scanning electron microscopy (SEM) micrographs and depth profiling by energy dispersive x-ray spectroscopy (EDX) were carried out on a Leo 1350 with a field emission cathode. The acceleration voltage for EDX was $8 \mathrm{keV}$; thus only the $L$-lines of the metals were analyzed.

\section{RESULTS}

All precursors were analyzed during an identical heating program as described in Sec. II. Figure 1 shows the experimental data recorded during the heating experiment on a precursor of the structure $\mathrm{Mo} / \mathrm{SnS} / \mathrm{CuS}$. The energy range from 23 to $36 \mathrm{keV}$ was selected to give an overview of all crystalline phases appearing during the experiment and the
TABLE II. List of phases that could be identified by XRD during the heating experiments for various precursor types. The diffraction signals of phases marked with an asterisk "*" disappear irreversibly in the course of the experiment. The diffraction signals of $\mathrm{ZnS}, \mathrm{Cu}_{2} \mathrm{SnS}_{3}$, and $\mathrm{Cu}_{2} \mathrm{ZnSnS}_{4}$ may overlap, and these phases are therefore combined in parentheses.

\begin{tabular}{|c|c|}
\hline Precursor & List of phases (and their temperature ranges in ${ }^{\circ} \mathrm{C}$ ) \\
\hline $\mathrm{Mo} / \mathrm{Sn}+\mathrm{S}$ & $\begin{array}{c}\mathrm{SnS}_{2}(20-360)^{*} \\
\mathrm{Sn}_{2} \mathrm{~S}_{3}(320-380)^{*} \\
\mathrm{SnS}(330-410)^{*}\end{array}$ \\
\hline $\mathrm{Mo} / \mathrm{Cu}+\mathrm{Sn}+\mathrm{S}$ & $\begin{array}{c}\mathrm{Cu}_{2} \mathrm{SnS}_{3}(20-470)^{*} \\
\mathrm{Cu}_{4} \mathrm{SnS}_{4}(400-500)^{*} \\
\mathrm{Cu}_{2-\mathrm{x}} \mathrm{S}(480-505)\end{array}$ \\
\hline $\mathrm{Mo} / \mathrm{Cu}+\mathrm{Zn}+\mathrm{Sn}+\mathrm{S}$ & {$\left[\mathrm{ZnS} / \mathrm{Cu}_{2} \mathrm{SnS}_{3} / \mathrm{Cu}_{2} \mathrm{ZnSnS}_{4}\right](20-505)$} \\
\hline $\mathrm{Mo} / \mathrm{SnS}$ & $\begin{array}{c}\operatorname{SnS}(20-480)^{*} \\
\operatorname{Sn}_{2} \mathrm{~S}_{3}(320-380)^{*}\end{array}$ \\
\hline $\mathrm{Mo} / \mathrm{SnS} / \mathrm{CuS}$ & $\begin{array}{c}\mathrm{CuS}(20-230) \\
\mathrm{SnS}(20-470)^{*} \\
\mathrm{Cu}_{2-\mathrm{x}} \mathrm{S}(230-505) \\
\mathrm{Cu}_{2} \mathrm{SnS}_{3}(20-485)^{*} \\
\mathrm{Cu}_{4} \mathrm{SnS}_{4}(390-505)\end{array}$ \\
\hline $\mathrm{Mo} / \mathrm{SnS} / \mathrm{CuS} / \mathrm{ZnS}$ & $\begin{array}{c}\mathrm{CuS}(20-350) \\
\mathrm{SnS}(20-470)^{*} \\
\mathrm{Cu}_{2-\mathrm{x}} \mathrm{S}(350-505) \\
{\left[\mathrm{ZnS} / \mathrm{Cu}_{2} \mathrm{SnS}_{3} / \mathrm{Cu}_{2} \mathrm{ZnSnS}_{4}\right](20-505)}\end{array}$ \\
\hline
\end{tabular}

development of the Sn $K$ fluorescence lines. During the experiment the ternary phases $\mathrm{Cu}_{2} \mathrm{SnS}_{3}$ and $\mathrm{Cu}_{4} \mathrm{SnS}_{4}$ form and the intensity of the $\mathrm{Sn} K \alpha$ fluorescence line decreases significantly.

Table II gives an overview of the development of phases for this and all other investigated precursors according to the detected diffraction signals. For the two precursors of the material system $\mathrm{Sn}-\mathrm{S}$ all diffraction signals of the film decrease below the detection limit in the course of the heating experiment. In both precursor types of the system $\mathrm{Cu}-\mathrm{Sn}-\mathrm{S}$ the phase $\mathrm{Cu}_{2} \mathrm{SnS}_{3}$ appears first and $\mathrm{Cu}_{4} \mathrm{SnS}_{4}$ second. As in the case of the $\mathrm{Sn}-\mathrm{S}$ phases the diffraction intensity of these phases falls below the detection limit within the heating experiment.

In the system $\mathrm{Cu}-\mathrm{Zn}-\mathrm{Sn}-\mathrm{S}$ the diffraction signals of the phase $\mathrm{Cu}_{2} \mathrm{ZnSnS}_{4}$ cannot be distinguished from the phases $\mathrm{ZnS}$ (sphalerite) and $\mathrm{Cu}_{2} \mathrm{SnS}_{3}$ due to their structural similarity. ${ }^{18}$ The diffraction peaks of these phases can overlap, and, for a more comprehensible representation, these peaks will be called $\Sigma$-signals in this paper, with the hklindices of the cubic sphalerite structure. Nevertheless we found significant differences in the film formation of the $\mathrm{Cu}-$ $\mathrm{Sn}-\mathrm{S}$ and the $\mathrm{Cu}-\mathrm{Zn}-\mathrm{Sn}-\mathrm{S}$ system. Figure 2 shows the deviations in the evolution of the $\mathrm{Sn} K \alpha$ fluorescence intensity for the different precursors. While for the $\mathrm{Cu}-\mathrm{Zn}-\mathrm{Sn}-\mathrm{S}$ system the Sn fluorescence intensity changes by less than $15 \%$ during the experiment, we find a strong decrease $(\mathrm{Mo} / \mathrm{SnS} /$ $\mathrm{CuS}$ precursor) and a complete disappearance $(\mathrm{Mo} / \mathrm{Cu}+\mathrm{Sn}$ $+\mathrm{S}$ precursor) of the $\mathrm{Sn}$ signal for the $\mathrm{Cu}-\mathrm{Sn}-\mathrm{S}$ system. Al- 


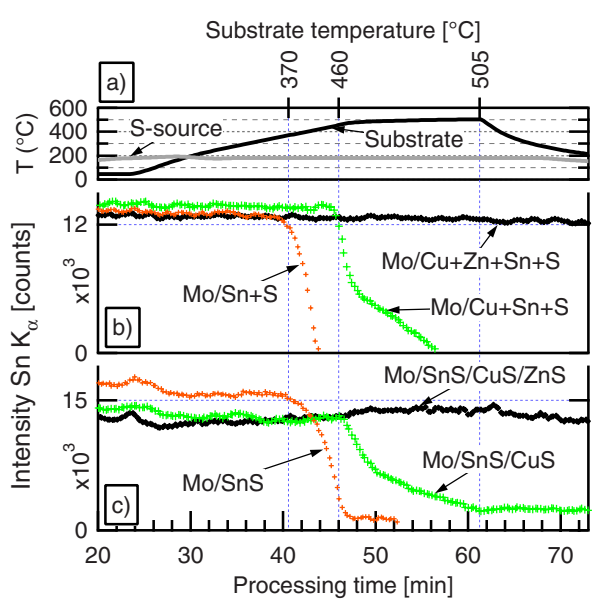

FIG. 2. (Color online) The intensity evolution of the Sn $K \alpha$ signal for the coevaporated precursors (b) and the sequentially evaporated precursors (c). The decrease in fluorescence intensity of the two tin sulfide films and the two copper tin sulfide films starts at similar temperatures. (a) gives the temperatures of the substrate and the S-source as functions of time.

though these two precursors have a different layout, the loss in $\mathrm{Sn} K \alpha$ intensity starts at a similar temperature of about $460{ }^{\circ} \mathrm{C}$. In the $\mathrm{Sn}+\mathrm{S}$ and $\mathrm{SnS}$ precursors the diminishing of the Sn $K \alpha$ line starts at even lower temperatures of approximately $370{ }^{\circ} \mathrm{C}$.

Figure 3 correlates the evolution of the fluorescence and diffraction signals for the precursor $\mathrm{Mo} / \mathrm{SnS} / \mathrm{CuS}$. The decrease in $\mathrm{Sn} K \alpha$ intensity at $470{ }^{\circ} \mathrm{C}$ coincides with the decrease in $\mathrm{Cu}_{2} \mathrm{SnS}_{3}$ and an increase in $\mathrm{Cu}_{4} \mathrm{SnS}_{4}$ diffraction intensity. At about $485{ }^{\circ} \mathrm{C} \mathrm{Cu}_{2} \mathrm{SnS}_{3}$ disappears completely and also $\mathrm{Cu}_{4} \mathrm{SnS}_{4}$ intensity starts to decrease. The $\mathrm{Cu}_{2-\mathrm{x}} \mathrm{S}$ diffraction signals augment with the decrease in $\mathrm{Cu}_{4} \mathrm{SnS}_{4}$ intensity.

This decrease in $\mathrm{Sn} K \alpha$ intensity was not found for the

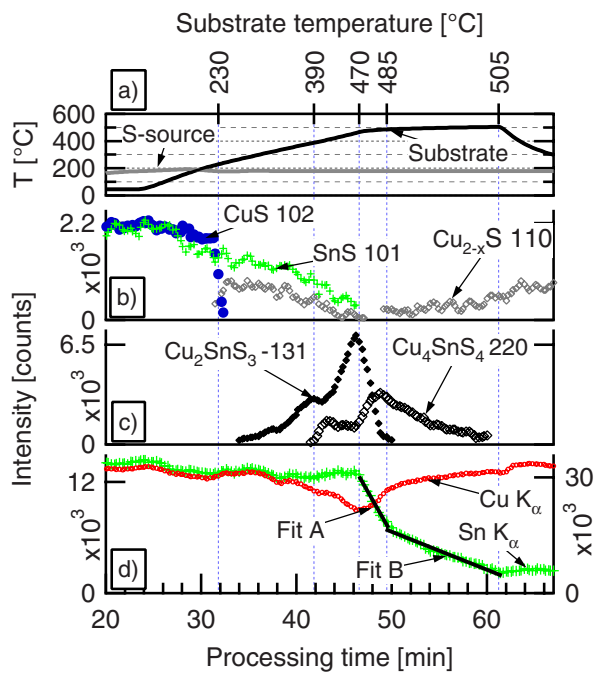

FIG. 3. (Color online) Signal intensities for the heating experiment on the precursor $\mathrm{Mo} / \mathrm{SnS} / \mathrm{CuS}$. The signal intensities of prominent diffraction peaks of the binary phases (b), the ternary phases (c), and the fluorescence lines (d) are depicted. For the decrease in the $\mathrm{Sn} K \alpha$ fluorescence intensity two regions were approximated by a linear curve fit. The slope of the first region was fitted to $-1850 \pm 70$ counts $/ \mathrm{min}$ (fit A) and of the second region to $-400 \pm 10$ counts/min (fit B). The intensity immediately before the start of the first region was approximated to $13000 \pm 300$ counts. (a) gives the temperatures of the substrate and the S-source as functions of time.

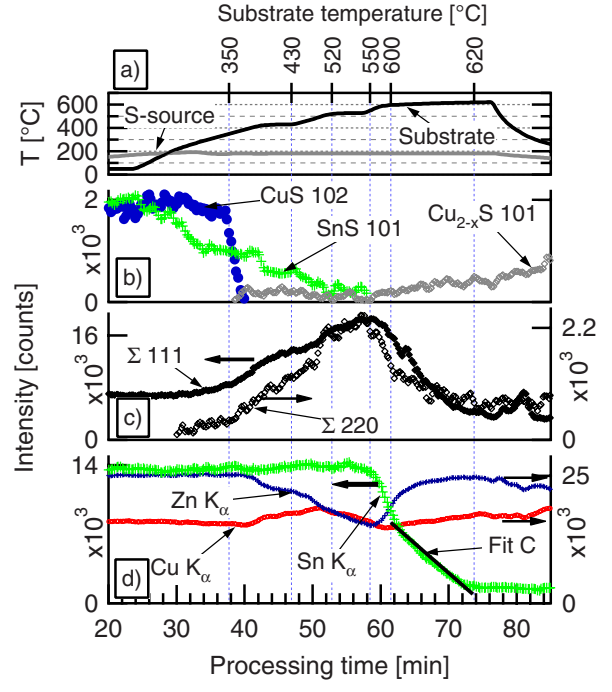

FIG. 4. (Color online) Signal intensities for the modified heating experiment on the precursor $\mathrm{Mo} / \mathrm{SnS} / \mathrm{CuS} / \mathrm{ZnS}$. The signal intensities of prominent diffraction peaks of the binary phases (b) and of the so-called $\Sigma$-signal are depicted [(c) the $\Sigma$-signal may be a sum of $\mathrm{Cu}_{2} \mathrm{ZnSnS}_{4}, \mathrm{Cu}_{2} \mathrm{SnS}_{3}$, and $\mathrm{ZnS}$ diffraction peaks]. (d) shows the evolution of the fluorescence lines of the different film elements. The decrease in the $\mathrm{Sn} K \alpha$ fluorescence intensity in the temperature region between 600 and $620^{\circ} \mathrm{C}$ was approximated by a linear curve fit. The slope was fitted to $-630 \pm 20$ counts/min (fit C), and the starting intensity was approximated to $13800 \pm 400$ counts. (a) gives the temperatures of the substrate and the $\mathrm{S}$-source as functions of time.

material system $\mathrm{Cu}-\mathrm{Zn}-\mathrm{Sn}-\mathrm{S}$ in the standard heating process (see Fig. 2). In order to examine the thermal activation of Sn loss in this material system, a heating process with higher temperatures was applied to a $\mathrm{Mo} / \mathrm{SnS} / \mathrm{CuS} / \mathrm{ZnS}$ precursor. Figure 4(a) shows the heating program for this experiment, which was based on three temperature dwells at approximately 420,530 , and $610{ }^{\circ} \mathrm{C}$. Figure $4(\mathrm{~b})$ depicts the intensities of diffraction peaks of the binary phases and Fig. 4(c) the intensities of two so-called $\Sigma$-signals, which may represent an overlap of the diffraction peaks of $\mathrm{Cu}_{2} \mathrm{ZnSnS}_{4}$, $\mathrm{Cu}_{2} \mathrm{SnS}_{3}$, and $\mathrm{ZnS}$ (sphalerite). The evolution of the fluorescence lines in Fig. 4(d) shows that also for the $\mathrm{Cu}-\mathrm{Zn}-\mathrm{Sn}-\mathrm{S}$ system a significant decrease in the $\mathrm{Sn} K \alpha$ signal is apparent for substrate temperatures exceeding $550{ }^{\circ} \mathrm{C}$. At a constant temperature of approximately $610^{\circ} \mathrm{C}$ the Sn fluorescence intensity decreases with a rate of 630 counts/min. With the Sn fluorescence signal also the intensities of the $\Sigma$-signals decrease while the $\mathrm{Cu}_{2-x} \mathrm{~S}$ diffraction peak becomes stronger.

For the interpretation of the decreasing $\operatorname{Sn} K \alpha$ signals it is advantageous to have information on the depth profile of the $\mathrm{Sn}$ share in the film before and after the drop in the $\mathrm{Sn}$ fluorescence signal in the film. Figure 5 depicts a SEM micrograph of the precursor $\mathrm{Mo} / \mathrm{SnS} / \mathrm{CuS} / \mathrm{ZnS}$ after the standard heating program (where no decrease in Sn $K \alpha$ intensity was observed; see Fig. 2). A porous bottom layer and a top layer with large, $\mathrm{Cu}$-rich grains can be discerned. In the bottom layer the $\operatorname{Sn} L$ fluorescence intensity exhibits a weak gradient toward the Mo backcontact. The micrograph in Fig. 6 is taken on the sample after the heating experiment with higher temperatures depicted in Fig. 4. The Sn signal is significantly lower than in Fig. 5 with a Sn gradient toward the backcontact. 


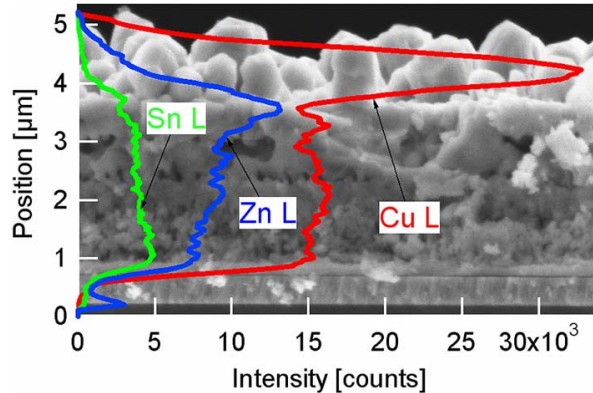

FIG. 5. (Color online) SEM cross section of the $\mathrm{Mo} / \mathrm{SnS} / \mathrm{CuS} / \mathrm{ZnS}$ precursor after the standard heating process (see Fig. 2). The micrograph is overlaid by the integrated fluorescence signals of an EDX scan on the micrograph area. The Mo and S signals are omitted.

\section{DISCUSSION}

The samples of all investigated material systems exhibit a significant decrease in the $\operatorname{Sn} K \alpha$ fluorescence intensity when processed at sufficiently high temperatures. This effect can be caused by (i) varying absorption in the surrounding and covering material or by (ii) a loss of $\mathrm{Sn}$ from the layer.

For point (i) the absorption by $\mathrm{Cu}, \mathrm{Zn}$, and $\mathrm{S}$ has to be taken into account. Absorption of the incoming radiation above the Sn $K \alpha$ edge $(29.2 \mathrm{keV})$, which can generate $\mathrm{Sn} K \alpha$ fluorescence, as well as absorption of the generated $\mathrm{Sn} K \alpha$ radiation $\left(\mathrm{E}_{K \alpha 1}=25.3 \mathrm{keV}, \mathrm{E}_{K \alpha 2}=25.0 \mathrm{keV}\right)$, has to be considered. The cross section for the absorption of photons in this energy range can be found in table works. ${ }^{19,20}$ With the cross section $\sigma$ and the particle density per area $\rho$, the ratio of absorbed intensity to start intensity $I_{\text {abs }} / I_{0}$ in a layer of thickness $x$ can be calculated according to Lambert-Beers law

$$
\frac{I_{\text {abs }}}{I_{0}}=1-\exp (-\sigma \rho x) .
$$

A $2 \mu \mathrm{m}$ thick layer of stoichiometric $\mathrm{Cu}_{2} \mathrm{ZnSnS}_{4}$ will have particle densities of $2.5 \times 10^{18}$ at. $/ \mathrm{cm}^{2}$ for $\mathrm{Cu}, 1.3$ $\times 10^{18}$ at. $/ \mathrm{cm}^{2}$ for $\mathrm{Zn}$, and $5.0 \times 10^{18}$ at. $/ \mathrm{cm}^{2}$ for S. To calculate an upper limit for the absorption effect we assume that the Sn share of the film is completely accumulated in a layer at the back of the film. Sn $K \alpha$ photons emitted from this layer will be absorbed to $7 \%$ by the covering $\mathrm{Cu}, 4 \%$ by $\mathrm{Zn}$, and $1 \%$ by $\mathrm{S}$, resulting in a total attenuation of the $\mathrm{Sn} K \alpha$

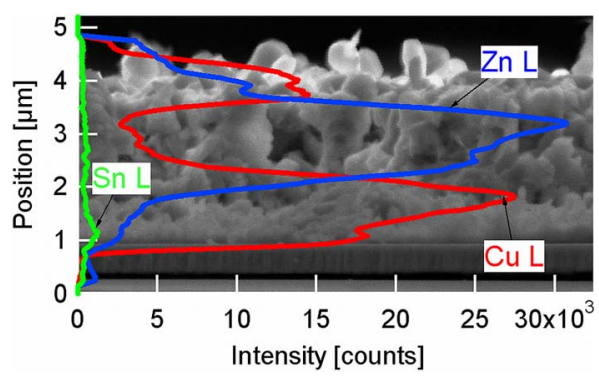

FIG. 6. (Color online) SEM cross section of the $\mathrm{Mo} / \mathrm{SnS} / \mathrm{CuS} / \mathrm{ZnS}$ precursor after the heating process with high temperatures depicted in Fig. 4. Like in Fig. 5 the micrograph is overlaid by the integrated fluorescence signals of an EDX scan on the micrograph area. It is possible that covering copper sulfide grains delaminated during preparation of the cross section. The Mo and S signals are omitted.
TABLE III. Rate of the Sn loss from the precursors according to curve fits (A) and (B) in Fig. 3, fit (C) in Fig. 4, and Eq. (2). The temperatures are given as mean, rounded values for the interval of the curve fit. The phases in parentheses are assumed to be the origin of the Sn loss for the different processing stages and precursors, based on the XRD data in Figs. 3 and 4.

\begin{tabular}{|c|c|c|}
\hline Precursor (phase with Sn loss) & $\begin{array}{c}\text { Temperature } \\
\left({ }^{\circ} \mathrm{C}\right)\end{array}$ & $\begin{array}{c}\text { Loss rate } \\
{\left[\text { at. } /\left(\mathrm{cm}^{2} \mathrm{~min}\right)\right]}\end{array}$ \\
\hline $\mathrm{Mo} / \mathrm{SnS} / \mathrm{CuS}\left(\mathrm{Cu}_{2} \mathrm{SnS}_{3}\right.$, fit A $)$ & 480 & $(1.6 \pm 0.5) \times 10^{17}$ \\
\hline $\mathrm{Mo} / \mathrm{SnS} / \mathrm{CuS}\left(\mathrm{Cu}_{4} \mathrm{SnS}_{4}\right.$, fit B $)$ & 495 & $(3.4 \pm 1.1) \times 10^{16}$ \\
\hline $\mathrm{Mo} / \mathrm{SnS} / \mathrm{CuS} / \mathrm{ZnS}\left(\mathrm{Cu}_{2} \mathrm{ZnSnS}_{4}\right.$, fit C) & 610 & $(5.1 \pm 1.7) \times 10^{16}$ \\
\hline
\end{tabular}

radiation by $12 \%$. The attenuation of the incoming photons above $29.2 \mathrm{keV}$, which excite the $\mathrm{Sn} K \alpha$ radiation, will be lower than this due to lower cross sections for the interaction with $\mathrm{Cu}, \mathrm{Zn}$, and $\mathrm{S}$ at higher energies. Thus, the change in Sn $K \alpha$ fluorescence due to changing elemental distribution in the film is less than $24 \%$. A generalized evaluation of the absorption of incoming and outgoing radiations based on first principles calculations can be found elsewhere ${ }^{21}$ and will not be discussed here. A good empirical approximation of the influence of the elemental depth gradient on Sn fluorescence intensity can be made on the following basis: In the $\mathrm{Mo} / \mathrm{SnS} / \mathrm{CuS} / \mathrm{ZnS}$ precursor $\mathrm{Sn}$ is, in fact, aggregated at the back of the film; the absorption by other constituents of the film should therefore be at a maximum. The EDX scan in Fig. 5 shows that $\mathrm{Sn}$ has distributed in the film during the annealing process at $500{ }^{\circ} \mathrm{C}$. The Sn intensity during this process increases by less than $15 \%$, according to the data in Figs. 2-4. A decrease in the Sn $K \alpha$ fluorescence intensity due to a change in the elemental depth distribution after this stage would therefore be limited to $15 \%$, because the precursor layering represents the condition of maximum absorption by covering material. We therefore conclude that point (ii), the loss of Sn from the layer, is the main cause for the decrease in $\mathrm{Sn} K \alpha$ fluorescence signal. This is confirmed by the disappearance of diffraction peaks of Sn-containing phases, the appearance of copper sulfides in Figs. 3 and 4, and the strong decrease in the Sn signal observed by EDX in Fig. 6.

If we neglect absorption effects the intensity of the Sn $K \alpha$ fluorescence signal depends linearly on the $\mathrm{Sn}$ amount in the layer. The evolution of the Sn amount $n_{\mathrm{Sn}}(t)$ in the layers can then be derived from the starting Sn amount $n_{\mathrm{Sn}, 0}$, the starting fluorescence intensity $I_{\mathrm{Sn} K \alpha, 0}$, and the evolution of the fluorescence intensity $I_{\mathrm{Sn} K \alpha}(t)$ by the linear relation

$$
n_{\mathrm{Sn}}(t)=n_{\mathrm{Sn}, 0} \frac{I_{\mathrm{Sn} K \alpha}(t)}{I_{\mathrm{Sn} K \alpha, 0}} .
$$

With respect to absorption effects we assume a maximum error for the fluorescence intensity of $15 \%$. Furthermore we approximate the error for the starting amount $n_{\mathrm{Sn}, 0}$, which is derived from the evaporation rates (see Table I for the values of $n_{\mathrm{Sn}, 0}$ ), to be less than $15 \%$. With $n_{\mathrm{Sn}, 0}$ from Table I and the intensities from Figs. 3 and 4 we can calculate $n_{\mathrm{Sn}}(t)$ according to Eq. (2). With the linear curve fits in Figs. 3 and 4 the Sn-loss rate can be approximated. The loss rates for the three different curve fits A-C are summarized in Table III. 
For the precursor Mo/SnS/CuS two stages of Sn loss can be discerned and correlated to the observed crystalline phases (see the XRD data in Fig. 1). In a first stage at about $480{ }^{\circ} \mathrm{C}$ the $\mathrm{Sn}$ loss is coupled with a decrease in $\mathrm{Cu}_{2} \mathrm{SnS}_{3}$ diffraction intensity while $\mathrm{Cu}_{4} \mathrm{SnS}_{4}$ increases. In the second stage at about $495{ }^{\circ} \mathrm{C} \mathrm{Cu}_{2} \mathrm{SnS}_{3}$ has vanished and the intensity of $\mathrm{Cu}_{4} \mathrm{SnS}_{4}$ decreases. We therefore conclude that in the first stage $\mathrm{Sn}$ is lost by the decomposition of $\mathrm{Cu}_{2} \mathrm{SnS}_{3}$ and in the second stage, significantly slower, by decomposition of $\mathrm{Cu}_{4} \mathrm{SnS}_{4}$. We found also for the precursor $\mathrm{Mo} / \mathrm{Cu}+\mathrm{Sn}+\mathrm{S}$ two stages of $\mathrm{Sn}$ loss, which could be related to the phases $\mathrm{Cu}_{2} \mathrm{SnS}_{3}$ and $\mathrm{Cu}_{4} \mathrm{SnS}_{4}$, respectively.

For the precursor Mo/SnS/CuS/ZnS the development of phases during $\mathrm{Sn}$ loss is more difficult to scrutinize because of the possible overlap of $\mathrm{ZnS}, \mathrm{Cu}_{2} \mathrm{SnS}_{3}$, and $\mathrm{Cu}_{2} \mathrm{ZnSnS}_{4}$ diffraction peaks. Nevertheless, with the results on the $\mathrm{Sn}$ loss from the ternary sulfides, it can be assumed that at $530{ }^{\circ} \mathrm{C}$, before the $\mathrm{Sn}$ loss from the Mo/SnS/CuS/ZnS stack starts, no copper tin sulfides are present as they should have been decomposed already at lower temperatures. We therefore postulate that the $\mathrm{Sn}$ loss from these layers can be traced back to the decomposition of $\mathrm{Cu}_{2} \mathrm{ZnSnS}_{4}$.

We still did not address the question in which form $\mathrm{Sn}$ is desorbed from the films. According to known data for the $\mathrm{Sn}$-vapor pressure ${ }^{22}$ it can be excluded that elemental $\mathrm{Sn}$ is evaporated from the films at a significant rate; the evaporated particles will therefore be molecules. In the material system $\mathrm{Cu}-\mathrm{Zn}-\mathrm{Sn}-\mathrm{S}$ the Sn-containing compounds can be tin sulfides, copper tin sulfides, or copper tin alloys. ${ }^{23,24}$ The evolution of the $\mathrm{Cu} K \alpha$ fluorescence during the heating experiment on the precursor Mo/SnS/CuS in Fig. 3 indicates that there is no loss of $\mathrm{Cu}$ from the films. We therefore conclude that the $\mathrm{Sn}$ loss is due to the evaporation of tin sulfide. This is also affirmed by the experimental finding in Fig. 2 where the films of the material system $\mathrm{Sn}-\mathrm{S}$ show $\mathrm{Sn}$ loss at lower temperatures as the other material systems. The high vapor pressure of tin sulfides has been the subject of several scientific publications. ${ }^{25-27}$ By mass spectrometric measurements the molecules in the gas phase could be identified as mainly SnS. ${ }^{28}$ The sulfur rich tin sulfides $\mathrm{SnS}_{2}$ and $\mathrm{Sn}_{2} \mathrm{~S}_{3}$ decompose firstly by desorbing sulfur and evaporating $\mathrm{SnS}$ at higher temperatures. ${ }^{27}$ We therefore conclude that in our experiments $\mathrm{SnS}$ is evaporated and suggest the following decomposition reactions (for simplification $\mathrm{Cu}_{2-x} \mathrm{~S}$ is approximated by $\left.\mathrm{Cu}_{2} \mathrm{~S}\right)$ :

$$
\begin{aligned}
& \text { (A) } 2 \mathrm{Cu}_{2} \mathrm{SnS}_{3}(\mathrm{~s}) \rightarrow \mathrm{Cu}_{4} \mathrm{SnS}_{4}(\mathrm{~s})+\mathrm{SnS}(\mathrm{g})+\mathrm{S}(\mathrm{g}), \\
& \begin{aligned}
\text { (B) } \mathrm{Cu}_{4} \mathrm{SnS}_{4}(\mathrm{~s}) \rightarrow & 2 \mathrm{Cu}_{2} \mathrm{~S}(\mathrm{~s})+\mathrm{SnS}(\mathrm{g})+\mathrm{S}(\mathrm{g}), \\
\text { (C) } \mathrm{Cu}_{2} \mathrm{ZnSnS}_{4}(\mathrm{~s}) \rightarrow & \mathrm{Cu}_{2} \mathrm{~S}(\mathrm{~s})+\mathrm{ZnS}(\mathrm{s})+\mathrm{SnS}(\mathrm{g}) \\
+ & \mathrm{S}(\mathrm{g}),
\end{aligned}
\end{aligned}
$$

where (s) denotes a solid state phase and (g) a gaseous phase. These reactions comply very well with the observed evolution of phases during Sn loss.

It is very plausible to assume that the Sn loss and the formation of the solid decomposition products start at the top of the film, where the gaseous phase desorbs. This is con-

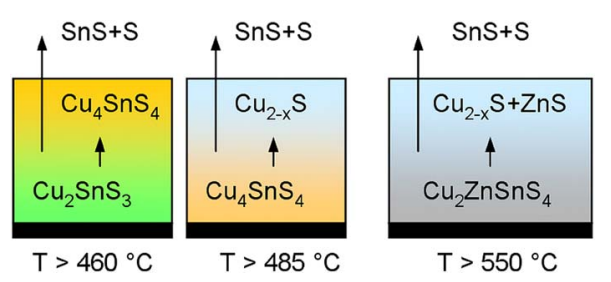

FIG. 7. (Color online) Schematic representation of the decomposition of different Sn-containing phases in thin films. The temperatures at the bottom correspond to the starting points of the decomposition as they were found in the experiments of Figs. 3 and 4.

firmed by the EDX depth profile in Fig. 6. On this basis a schematic of the Sn loss from thin films of the different phases is drawn in Fig. 7.

Although there are some reports in literature about annealing experiments on $\mathrm{Cu}-\mathrm{Zn}-\mathrm{Sn}-\mathrm{S}$ films at temperatures of $550{ }^{\circ} \mathrm{C}$ and above ${ }^{29-31}$ a significant $\mathrm{Sn}$ loss from these films has never been observed. All of these cited annealing experiments were carried out in $\mathrm{N}_{2}+\mathrm{H}_{2} \mathrm{~S}$ atmosphere. For evaporation in vacuum the maximum evaporation rate $d n / d t$ per area $A$ can be expressed by kinetic gas theory (HertzKnudsen equation ${ }^{32,33}$ ) to

$$
\frac{d n}{A d t}=\sqrt{\frac{1}{2 \pi m k_{B} T}} p^{*},
$$

where $m$ is the mass of the evaporant particles, $k_{B}$ is the Boltzmann constant, and $p^{*}$ is the equilibrium vapor pressure of the evaporating species at the temperature $T$. If the evaporation process is not carried out in vacuum but in a gas atmosphere the kinetic gas theory approach of the HertzKnudsen equation is not applicable anymore. The evaporant particles collide with the surrounding gas particles and the evaporation will be controlled by diffusion and convection in the surrounding gas phase. ${ }^{34}$ As a general rule it can be stated, also on the basis of several experimental works, ${ }^{32,35,36}$ that due to this effect the evaporation rate in an inert gas atmosphere is always lower than in vacuum. We argue therefore that the $\mathrm{N}_{2}+\mathrm{H}_{2} \mathrm{~S}$ atmosphere of the experiments cited above $^{29-31}$ explains the missing Sn loss in those cases.

\section{CONCLUSION}

By the application of in situ XRD and XRF we could show that for a pressure of $1 \times 10^{-2} \mathrm{~Pa}$ and temperatures above $350{ }^{\circ} \mathrm{C}$ thin films of the material systems $\mathrm{Sn}-\mathrm{S}, \mathrm{Cu}-$ $\mathrm{Sn}-\mathrm{S}$, and $\mathrm{Cu}-\mathrm{Zn}-\mathrm{Sn}-\mathrm{S}$ evaporate $\mathrm{SnS}$. Ternary $\left(\mathrm{Cu}_{2} \mathrm{SnS}_{3}\right.$ and $\left.\mathrm{Cu}_{4} \mathrm{SnS}_{4}\right)$ and quaternary $\left(\mathrm{Cu}_{2} \mathrm{ZnSnS}_{4}\right)$ phases decompose and copper sulfides and zinc sulfides remain as solid phases in the film. The evaporation rate from the different phases increases according to the sequence $\mathrm{Cu}_{2} \mathrm{ZnSnS}_{4}$ $\rightarrow \mathrm{Cu}_{4} \mathrm{SnS}_{4} \rightarrow \mathrm{Cu}_{2} \mathrm{SnS}_{3} \rightarrow \mathrm{SnS}$. For $\mathrm{Cu}_{2} \mathrm{ZnSnS}_{4}$ a $\mathrm{SnS}$ loss with significant rates occurs at temperatures of $550{ }^{\circ} \mathrm{C}$ and above. These high temperatures are usually applied to the deposition of $\mathrm{Cu}(\mathrm{In}, \mathrm{Ga}) \mathrm{Se}_{2}$ absorber films and appear to be beneficial for device quality. ${ }^{37}$ For the PVD of $\mathrm{Cu}_{2} \mathrm{ZnSnS}_{4}$ in this temperature region the loss of $\mathrm{SnS}$ from the layers has to be considered. An additional inert gas atmosphere can suppress material transport through the gas phase and therefore reduce $\mathrm{SnS}$ evaporation from the substrate. A feasible 
method for the deposition of $\mathrm{Cu}_{2} \mathrm{ZnSnS}_{4}$ thin films may therefore include thin film deposition by PVD at temperatures below $550{ }^{\circ} \mathrm{C}$ and a subsequent annealing step in inert gas atmosphere to improve crystal quality.

\section{ACKNOWLEDGMENTS}

The help of Dr. T. Wroblewski at beamline F3 of the HASYLAB facility is gratefully acknowledged. Mo-coated substrate glasses were supplied by Jo Klaer, Bianka Bunn, and Norbert Blau.

${ }^{1}$ K. Ito and T. Nakazawa, Jpn. J. Appl. Phys., Part 1 27, 2094 (1988).

${ }^{2}$ H. Katagiri, K. Jimbo, S. Yamada, T. Kamimura, W. S. Maw, T. Fukano, T. Ito, and T. Motohiro, Appl. Phys. Express 1, 041201 (2008)

${ }^{3}$ S. R. Hall, J. T. Szymanski, and J. M. Stewart, Can. Mineral. 16, 131 (1978).

${ }^{4}$ J. Paier, R. Asahi, A. Nagoya, and G. Kresse, Phys. Rev. B 79, 115126 (2009).

${ }^{5}$ S. Chen, X. G. Gong, A. Walsh, and S. H. Wie, Appl. Phys. Lett. 94, 041903 (2009).

${ }^{6}$ S. Schorr, Thin Solid Films 515, 5985 (2007).

${ }^{7}$ T. M. Friedlmeier, H. Dittrich, and H. W. Schock, Proceedings of the 11th International Conference on Ternary and Multinary Compounds (ICTMC), Salford, 1997 (unpublished), p. 345.

${ }^{8}$ T. Tanaka, D. Kawasaki, M. Nishio, Q. Guo, and H. Ogawa, Phys. Status Solidi C 3, 2844 (2006).

${ }^{9}$ A. Weber, H. Krauth, S. Perlt, B. Schubert, I. Kötschau, S. Schorr, and H. W. Schock, Thin Solid Films 517, 2524 (2009).

${ }^{10}$ K. Oishi, G. Saito, K. Ebina, M. Nagahashi, K. Jimbo, W. S. Maw, H. Katagiri, M. Yamakazi, H. Araki, and A. Takeuchi, Thin Solid Films 517, 1449 (2008).

${ }^{11}$ M. A. Contreras, M. J. Romero, and R. Noufi, Thin Solid Films 511-512 51 (2006)

${ }^{12}$ Ch. von Klopmann, J. Djordjevic, and R. Scheer, J. Cryst. Growth 289, 113 (2006).

${ }^{13}$ K. Koto and N. Morimoto, Acta Crystallogr., Sect. B: Struct. Crystallogr. Cryst. Chem. 26, 915 (1970).
${ }^{14}$ T. Chattopadhyay, J. Pannetier, and H. G. von Schnering, J. Phys. Chem. Solids 47, 879 (1986).

${ }^{15}$ M. Onoda, X. Chen, M. Sato, and H. Wada, Mater. Res. Bull. 35, 1563 (2000).

${ }^{16}$ P. S. Jaulmes, J. Rivet, and P. Laruelle, Acta Crystallogr., Sect. B: Struct. Crystallogr. Cryst. Chem. 33, 540 (1977).

${ }^{17}$ M. Oliveria, R. K. McMullan, and B. J. Wünsch, Solid State Ionics 28-30, 1332 (1988).

${ }^{18}$ F. Hergert and R. Hock, Thin Solid Films 515, 5953 (2007).

${ }^{19}$ D. C. Creagh and J. H. Hubbell, X-Ray Absorption (or Attenuation) Coefficients, International Tables for Crystallography Vol. C (Kluwer, Dordrecht, 1992), Sec. 4.2.4, pp. 189-206.

${ }^{20}$ J. H. Scofield, "Theoretical photoionization cross sections from 1 to 1500 keV," LLNL Report No. UCRL-51326, 1973.

${ }^{21}$ R. Mainz, "In-situ analyse und wachstum photovoltaischer absorber mit bandlückengradienten," Ph.D. thesis, Free University Berlin, 2008.

${ }^{22}$ F. Geiger, C. A. Busse, and R. I. Loehrke, Int. J. Thermophys. 8, 425 (1987).

${ }^{23}$ G. H. Moh, Chem. Erde 34, 1 (1975).

${ }^{24}$ I. D. Olekseyuk, I. V. Dudchak, and L. V. Piskach, J. Alloys Compd. 368, 135 (2004).

${ }^{25}$ A. W. Richards, Trans. Faraday Soc. 51, 1193 (1955).

${ }^{26}$ H. Wiedemeier and J. S. Csillag, Thermochim. Acta 34, 257 (1979).

${ }^{27}$ V. Piacente, S. Foglia, and P. Scardala, J. Alloys Compd. 177, 17 (1991).

${ }^{28}$ R. Colin and J. Drowart, J. Chem. Phys. 37, 1120 (1962).

${ }^{29}$ H. Katagiri, Thin Solid Films 480-481, 426 (2005).

${ }^{30}$ T. Kobayashi, K. Jimbo, K. Tsuchida, S. Shinoda, T. Oyanagi, and H. Katagiri, Jpn. J. Appl. Phys., Part 1 44, 783 (2005).

${ }^{31}$ K. Jimbo, R. Kimura, T. Kamimura, S. Yamada, W. S. Maw, H. Araki, K. Oishi, and H. Katagiri, Thin Solid Films 515, 5997 (2007).

${ }^{32}$ H. Hertz, Ann. Phys. 253, 177 (1882).

${ }^{33}$ M. Knudsen, Ann. Phys. 352, 697 (1915).

${ }^{34}$ C. Boyadjiev and B. Boyadjiev, Int. J. Heat Mass Transfer 46, 1679 (2003).

${ }^{35}$ G. R. Fonda, Phys. Rev. 21, 343 (1923).

${ }^{36}$ E. Fromm, Metall. Trans. A 9A, 1835 (1978).

${ }^{37}$ C. A. Kaufmann, R. Caballero, T. Unold, R. Hesse, R. Klenk, S. Schorr, M. Nichterwitz, and H. W. Schock, Sol. Energy Mater. Sol. Cells 93, 859 (2009). 